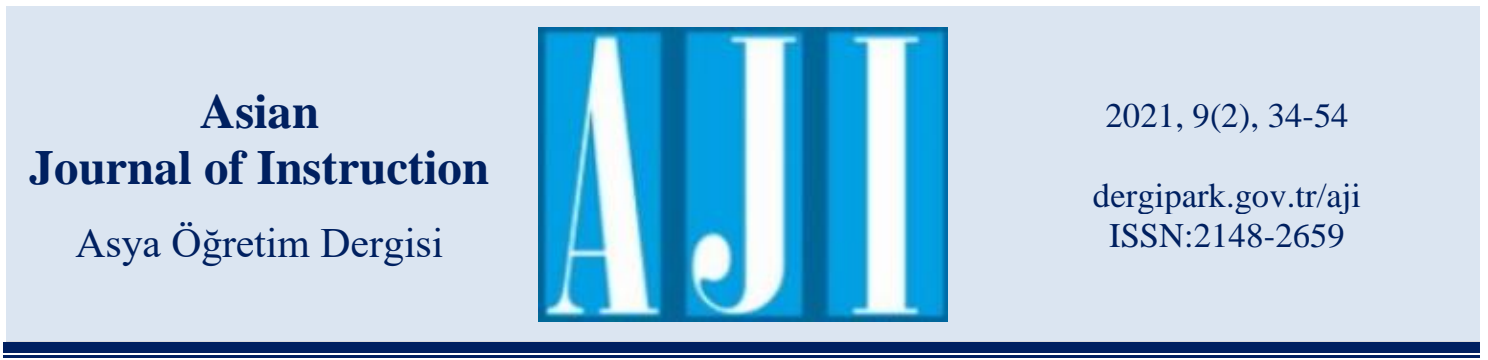

Geliş Tarihi: 27/07/2021

Kabul Tarihi: $21 / 11 / 2021$

Yayınlanma Tarihi: 31/12/2021

\title{
Mobil-FeTeMM Öğretim Uygulamalarının Öğretmen Adaylarının Mühendislik Tasarım Süreç Becerilerine Etkisi*
}

\author{
Suat Türkoğuz ${ }^{1}$, Ali Kayalar ${ }^{2}$
}

Türkoğuz, S., \& Kayalar, A. (2021). Mobil-FeTeMM öğretim uygulamalarının öğretmen adaylarının mühendislik tasarım süreç becerilerine etkisi. Asian Journal of Instruction, 9(2), 34-54. https://doi.org/10.47215/aji.974899

\section{$\ddot{O} \mathbf{z}$}

Çalışma mobil-FeTeMM öğretim uygulamalarının öğretmen adaylarının mühendislik tasarım süreç becerilerine etkisini incelemeyi amaçlamaktadır. Bu çalışma deneysel araştırma modellerinden ön test-son test denkleştirilmemiş kontrol gruplu yarı deneysel araştırma modeline göre tasarlanmıştır. Bu çalışmanın katılımcıları Dokuz Eylül Üniversitesi Buca Eğitim Fakültesi Fen Bilgisi Öğretmenliği programı üçüncü sınıfının iki farklı şubesinde kayıtlı öğretmen adaylarıdır. Ders döneminin başında yansız atama yöntemine göre bu iki sınıftan biri deney grubu (n: 45) ve diğeri de kontrol grubu (n: 25) olarak belirlenmiştir. Deney grubunda mobil-FeTeMM öğretim uygulamaları; kontrol grubunda ise sadece FeTeMM öğretim uygulamaları gerçekleştirilmiştir. Bu çalışmada Türkçeye uyarlanmış "Mühendislik Tasarım Süreç Becerileri Ölçeği” kullanılmıştır. Sonuç olarak çalışma, mobil-FeTeMM öğretim uygulamalarının öğretmen adaylarının mühendislik tasarım süreci becerilerini kontrol grubuna göre etkili bir şekilde geliştiremediğini göstermiştir. Ayrıca hem deney hem de kontrol grubundaki öğretmen adayları FeTeMM öğretim uygulamalarını gerçekleştirirken alternatif tasarım üretme, model geliştirme ve tasarlanan ürünü revize etme ile ilgili mühendislik tasarım süreç becerilerinde zorlanmışlardır. FeTeMM öğretim uygulamalarının amacına ulaşması için öğretmen adaylarının mobil teknolojilerinin sensör özelliklerini etkin kullanması ve tasarım becerilerinin gelişmiş olmasi gerekmektedir.

Anahtar Kelimeler: FeteMM, mobil teknoloji, mühendislik tasarım süreç becerileri

\section{The Effect of Mobile-STEM Teaching Implementations on Engineering Design Process Skills of Pre-service Teachers}

\begin{abstract}
The study examined the effects of mobile-STEM teaching implementations on pre-service teachers' engineering design process skills. The study was designed by pre-test-post-test nonequivalent control group quasi-experimental research model from experimental research models. The participants of the study were the pre-service teachers of two different classrooms in the third-grade on Science Teaching Program, Buca Faculty of Education, Dokuz Eylul University. At the beginning of the academic semester, a class was assigned randomly as the experimental group (n: 45) and the other class as the control group (n: 25). While the mobile-STEM teaching implementations were applied in the experimental group, only STEM teaching implementations were conducted in the control group. In this study, the adapted Turkish

\footnotetext{
* Bu çalışma Dokuz Eylül Ünivesitesi Eğitim Bilimleri Enstitüsü bünyesinde yürütülen tez çalışmasından üretilmiştir.

${ }^{1}$ Doç. Dr., Dokuz Eylül Üniversitesi, https://orcid.org/0000-0002-7850-2305, suat.turkoguz@ gmail.com

2 Doktora öğrencisi, Dokuz Eylül Üniversitesi, https://orcid.org/0000-0003-3324-7950, alikayalar1907@gmail.com
} 
Mobil-FeTeMM Öğretim Uygulamalarının Öğretmen Adaylarının Mühendislik Tasarım Süreç Becerilerine Etkisi

form of the "Engineering Design Process Skills Scale" was used. Consequently, the study showed that mobile-STEM teaching implementations did not improve pre-service teachers' engineering design process skills effectively compared to the control group. Additionally, pre-service teachers in both the experimental and control groups had difficulties in engineering design process skills related to producing alternative designs, developing models and revising the designed product while performing STEM teaching implementations. Pre-service teachers who want to reach their educational purposes with STEM teaching implementations should use the sensor features of mobile technologies effectively and develop their design skills.

Keywords: Engineering design process skills, mobile technology, stem

\section{Giriş}

Günümüzde teknolojik ve bilimsel gelişmelerin hızlı artışı, çağın gerektirdiği yeniliklere ayak uydurmak isteyen toplumlarda araştıran, üreten, sorgulayan, yaratıcı ve analitik düşünen bireylere duyulan ihtiyacı ortaya çıkarmıştır (Asunda, 2012; Yenilmez \& Balbağ, 2016). Ülkelerin ihtiyaç duyduğu nitelikte bireylerin yetiştirilmesi için gerekli olan becerilerin, bireylere kazandırılmasında fen ve matematik önemli rol oynamaktadır. Fen ve matematik öğretimine önem veren ülkelerin teknoloji ve bilgi üretimi de fazladır. Bilgi boyutunda öğrenilen matematik ve fen bilimlerinin uygulaması da mühendislik ve teknoloji ile yapılmaktadır. Teknoloji ve mühendislik, modern hayatta mevcut ve gelecekteki sorunlara önemli çözümler sunmaktadır (NRC, 2012; Yamak, Bulut \& Dündar, 2014). Teknolojinin gelişimine paralel olarak toplumların çoğu son yıllarda öğretim programlarında teknoloji destekli yenilikçi yaklaşımlara yönelmiştir (Balay, 2004). Ekonomik kalkınma ve yenilikçi teknolojilerin gerisinde kalmamak adına geleceğin mühendis beyinlerin yetişmesinde Fen, Teknoloji, Mühendislik ve Matematik (FeTeMM) okuryazarlığının kazandırılması oldukça önemlidir (Miaoulis, 2009). FeTeMM öğretim uygulamalarında teknolojiyi etkili kullanabilmek için pedagojik ve alan bilgisinin yanında mühendislik tasarım becerileriyle donanımlı ve nitelikli öğretmenlerin yetiştirilmesi gerekmektedir (Gündüz \& Odabaşı, 2004; Kirschner \& Selinger, 2003). Bu bağlamda fen ve matematik öğretiminin yanında mühendislik tasarım becerilerinin de kazandırılması önem kazanmaktadır (Yamak vd., 2014).

Bir sunum materyali olarak TV ve bilgisayar gibi teknolojilerin kullanımı mobil teknolojilere göre daha yoğundur. Bu anlamda, okullarda akıllı telefonların yer aldığı mobil teknolojilerin kullanımı nispeten yeni sayılabilir (Kearney \& Maher, 2013). Mobil teknolojiler 2000'li yıllardan itibaren yaşamın bir parçası olmaya başlamış ve son günlerde neredeyse bilgisayarların yerini aktif bir şekilde alarak günlük yaşamı etkilemiştir. Günümüzde ise çocukların çoğu bilgisayar ve mobil teknolojilerle erken yaşlarda tanışmakta ve çok küçük yaşlardan itibaren mobil teknolojilere aşina olmaktadır. Bu anlamda mobil teknolojiler günlük yaşamın bir gerçeği, hem öğrenciler hem de veliler için günlük yaşamın vazgeçilmez bir parçasıdır. Günümüzde bilgiye erişmek o kadar kolay olmuş; ancak ihtiyaç duyulan doğru bilgiye erişmek de bir o kadar zorlaşmıştır. Bu noktada öğretmen kontrolünde mobil teknolojiler, bilgiye ulaşmada yardımcı olabilir (Chou, Block \& Jesness, 2012), konuları daha anlaşılır hale getirebilir ve öğrencilerin derse olan katılımını artırabilir (Ariffin, Firdaus \& Mutalib, 2018; Nithia, Yusop \& Razak, 2015). Mobil teknolojilerin kolay taşınması ve öğrenme ortamlarına uygun olması da bir avantajdır (Tantu, 2017). Bu avantaj FeTeMM etkinliklerini laboratuvarın dışında yapma olanağı da sunar. Ayrıca mobil teknolojilerin çoklu sensörlere sahip olması da laboratuvarlardaki öğrenme ortamlarına bir avantaj sağlamaktadır. Çünkü çoğu okulların laboratuvarlarında dijital ölçme araçları bulunmamakta, bulunanların da yapısı hem karmaşık hem de parçaları pahalıdır. Laboratuvarlar, mevcut şartlarıyla öğrencilerin gerek duyduğu gözlem ve ölçme işlemleri için yetersizdir (Nunn, 2016). Bu durum, başta FeTeMM okuryazarlı̆ğ olmak üzere diğer becerilerin kazanılmasını zorlaştırmaktadır. Günümüzdeki mobil cihazlar mevcut çoklu sensörler ve bunlara entegre uygulamalarla laboratuvarlarda kullanılan birçok ölçüm cihazının görevini üstlenir 
duruma gelmiştir. Mobil teknolojilerin kamera ve sensörlerinden yararlanarak verileri toplamak, toplanan verileri daha sonra bilgisayara ortamına aktararak analiz etmek, yapılan deneylerdeki ölçme hatalarının en aza indirilmesini sağlamaktadır. Mobil teknolojilerin böylesi avantajlı yönleri, okullarda deney yapma ya da FeTeMM öğretim uygulamalarında sağliklı veri toplama sürecini teşvik edebilir. Ancak mobil teknolojilerin bu kadar avantajlı yönlerinin yanında dezavantajlı yanları da bulunmaktadır. Mobil cihazların fiyatlarının yüksek olması nedeniyle FeTeMM öğretim etkinlikleri sırasında cihazların zarar görebileceği kaygısı öğrencilerde bir tereddüt oluşturabilir. Bunun yanı sıra dikkat dağıtıcı uygulamalara yönelme ihtimalinin yüksek olması öğrencileri konunun odağından uzaklaştırabilir.

Öğrenilen bilginin kalıcı olması ve bilginin uygulama sahası bakımından FeTeMM öğretiminde mühendislik tasarım süreçleri önemlidir (Kolodner, 2002). Eğer öğrenciler FeTeMM öğretiminde mühendislik tasarım süreçleriyle yetişirse, sistematik düşünerek sorgulama becerisi kazanabilir ve günlük yaşamda karşılaşılan sorunlara çoklu çözümler üretebilir (Baran \& Kahraman, 2004; Bybee, 2011; Lou, Shih, Diez \& Tseng, 2011). Ancak FeTeMM öğretim uygulamalarıyla ilgili bazı araştırmalarda öğrencilerin problem belirleme, tasarım geliştirme, alternatif tasarım geliştirme, tasarımı değerlendirme ve revize etme süreçlerinde zorlandığ 1 ifade edilmiştir (English, King \& Smeed, 2017; Mentzer, Becker \& Sutton, 2015; Topalsan, 2018). Böyle bir durumda mobil teknolojilerin avantajlı yönleri, öğrencilerin zorlandıkları mühendislik tasarım süreçlerine yardımcı olabilir. Ancak mobil teknolojilerin dezavantajlı yönleri de mühendislik tasarım süreçlerini olumsuz etkileyebilir. Bu ikilem doğrultusunda çalışmada mobil teknolojiye dayalı FeTeMM (mobil-FeTeMM) öğretim uygulamalarının öğretmen adaylarının mühendislik tasarım süreç becerilerine etkisinin incelenmesi amaçlanmıştır. Bu maksatla araştırma sorusu "Mobil-FeTeMM öğretim uygulamalarının öğretmen adaylarının mühendislik tasarım süreç becerilerine etkisi nedir? şeklinde ifade edilmiştir.

\section{1. Çalışmanın Kuramsal Yapısı}

\subsubsection{FeTeMM Öğretim Yaklaşımı}

Gelişen ve küreselleşen dünyaya ayak uydurmak isteyen, teknolojilerin gerisinde kalmamak için çözüm arayan ülkeler öğretim programlarını yenilemektedirler. Bazı ülkeler yeniliklere açık olabilme adına geleceğin mühendislerini, bilim insanlarını ve matematikçilerini daha iyi yetiştirmek için eğitim alanında FeTeMM öğretim yaklaşımıyla reform hareketi yapmışlardır (Toulmin \& Groome, 2007). FeTeMM; fen, teknoloji, mühendislik ve matematik disiplinlerinin bütünleşik bir şekilde öğretildiği, genel olarak okul öncesinden doktora seviyesine kadar hem formal hem de informal öğrenme ortamlarında tüm sınıf düzeylerinde öğretim etkinlikleri içeren disiplinler arası öğrenme yaklaşımıdır (Çorlu, 2014; Dugger, 2010; Gonzalez \& Kuenzi, 2012; Sanders, 2009). Bybee'ye (2013) göre FeTeMM öğretim yaklaşımı, diğer eğitim reformlarından farklı olarak küresel ekonomik zorluklardan kaynaklanan kaygıları azaltmayı ve dünyanın teknolojik ve çevresel sorunlarının üstesinden gelmeyi hedefler. Bu bağlamda FeTeMM öğretim yaklaşımı, günlük yaşamla ilgili sorunlara birden fazla çözümlerin üretildiği, merkezinde teknolojiye dayalı mühendislik tasarımının olduğu araştırma-sorgulama, probleme dayalı öğrenme ve proje tabanlı öğrenme yaklaşımlarını içeren bir süreç olarak tanımlanabilir.

Okulların alt yapı yetersizliği ve öğretim programlarının farklı kültürlerden adaptasyonundan dolayı FeTeMM öğretiminin paydaşları olan fen, teknoloji, mühendislik ve matematik disiplinleri tam olarak entegre edilememektedir (Bybee, 2011; National Research Council [NRC], 2012). Bu durumda FeTeMM öğretim yaklaşımı farklı model biçimleriyle eksik bir biçimde ele alınmaktadır (Dugger, 2010; Sanders, 2009). Odak noktalarının çoğu, öğretim programında yer alan ayrı ayrı olarak fen veya matematik derslerine diğer FeTeMM disiplinlerinin dâhil edilmesidir (Bybee, 2011). Gerçek FeTeMM öğretim sürecinde fen, teknoloji, mühendislik ve matematik 
disiplinlerinin eşdeğer bir biçimde mühendislik ve tasarıma olanak sağlayacak şekilde düzenlenmesi gerekmektedir (Daugherty, 2012; MEB, 2018). Bu yaklaşıma göre fen dersine mühendislik tasarım sürecinin eklenmesi en uygun yol olarak görülmektedir (Bybee, 2010). Fen derslerinin mühendislik tasarım sürecine göre günlük yaşam problemleri çerçevesinde yürütülmesi yalnızca öğrencilerin hedeflenen fen kavramlarını ve kazanımlarını anlamlı öğrenmelerine imkân sağlamakla kalmaz, aynı zamanda öğrencilerin mühendislik disiplinine yönelik kavramsal anlayışlarını ve mühendislik tasarım süreci becerilerini de geliştirir (Daugherty, 2012; Dugger, 2010; NRC, 2012; Ryan, Camp \& Crismond, 2001).

\subsubsection{Mobil Teknolojiler ve Mobil Öğrenme}

Yarı iletkenlerin ve mikroçiplerin yer aldığı mikro elektronikteki yenilikler bilgisayar, mobil, bilgi, iletişim ve teknolojilerinin gelişmesinde etkili olmuştur (Atılgan, 2006). Cep telefonlarının, akı1lı telefonların ve tabletlerin böylesine çok yönlü piyasaya girişi, yediden yetmişe birçok kişinin bu mobil teknolojilere yönelimini artırmıştır. Bu teknolojilerde iletişim ve medya ortamlarının kolay kullanılabilmesi ve paylaşılabilmesi teknolojinin yaygınlaşması ve gelişmesinde büyük bir etken olmuştur (Briz-Ponce, Pereira, Carvalho, Juanes-Méndez \& GarcíaPeñalvo, 2017). Mobil teknolojilerin günlük yaşamda ve tıp, mühendislik, eğitim, iş dünyası, medya dünyası gibi her meslek grubunda çokça kullanıldığı görülmektedir (Ally, 2007). Hatta günümüzde mobil teknolojiler ile entegre edilebilen giyilebilir biyomedikal sensörlerin insan bedenine entegre edilmesi, hastalıkların takibini mümkün kılmaktadır (Hamida, Hamida \& Ahmed, 2015). Önümüzdeki yıllarda Endüstri 4.0 bünyesinde değerlendirilen mobil teknolojilerin gelişerek yaygınlaşması birtakım mesleklerin ortadan kalkmasına, pek çok yeni mesleğin de ortaya çıkmasına sebep olacaktır (Çark, 2020). Mobil teknolojilerin birçok alanda mesleklere olan etkisi temel alındığında öğretmenlik mesleği de bu bilgi, iletişim ve teknolojilerinden etkilenmiştir. Mobil teknolojilerin hızlı gelişimi, eğitimde öğretmen ve öğrencilerin bilgi, iletişim ve teknoloji yeterliklerinin iyileştirilmesi gereksinimini ortaya çıkarmıştır.

Mobil öğrenme, zaman ve mekân kısıtlamaları olmaksızın öğrenmeyi desteklemek için teknolojik bilgi veya konu içeriği sağlayan her türlü destek veya fırsat olarak tanımlanmaktadır (Lehner \& Nosekabel, 2002; Liu, Peng, Wu \& Lin, 2009). Mobil teknolojilerin öğretim ortamına entegre edilmesi, günlük yaşam problemleri ile ilgili materyale erişimin alternatif bir yolunun pratik olmadığı durumlarda öğrencilerin öğrenim olanaklarının geniş̧letilmesini, öğrenci performansının geliştirilmesini ve çeşitli stillerle öğrenmenin arttırılmasını sağlar (Kukulska-Hulme, 2009). Dünyada eğitimin her alanında kablosuz, mobil, taşınabilir teknolojik cihazların pedagojik kullanımı giderek daha fazla artmakta ve çeşitli kullanımları ortaya çıkmaktadır (Traxler, 2007). Daha iyi bir eğitim için mobil öğrenmenin benzersiz firsatları şu şekilde sıralanabilir: zamana ve mekâna bakılmaksızın öğrenmeyi sağlar, düşük gelirli öğrencilere ulaşmayı sağlar, 21. yy iletişim becerilerini geliştirir, farklı öğrenme ortamlarında öğrenmeyi kolaylaştırır ve bireysel farklılıkları ortadan kaldıracak şekilde her öğrenciye uygun bir şekilde uyarlanabilir (Chiong \& Shuler, 2010).

\subsubsection{Mühendislik Tasarım Süreci}

Mühendislik, fikirlerin ve teknolojinin insan yaşam kalitesini artıran ürün ve hizmetlere dönüştürme faaliyetleridir. Mühendislik, toplumların ihtiyaç ve istekleri için teknolojiyi yaratan, sürdüren, geliştiren ve uygulayan çabalar bütünüdür. Kökenleri, aletlerin ilk yaratıldığı ve geliştirildiği insan uygarlığının en başlangıcına kadar uzanır. Mühendislik, doğal dünyada var olmayan ve bazı insan istek ve ihtiyaçlarını karşılayan nesnelerin yaratılması, sürdürülmesi ve geliştirilmesidir (Burrus, 2009). Fen bilimleri ve mühendisliğin konu kapsamları birbirine benzese de bazı yönlerden birbirinden ayrılırlar. Fen bilimleri, nesnel dünyayı açıklamayı amaçlarken; mühendislik, gerçek yaşamda karşılaşılan problemlere veya ihtiyaçlara çözüm 
getirmeyi amaçlar (Brunsell, 2012). Fen bilimleri ve mühendisliğin problem çözüm sonuçları birbirinden tamamen farklılık göstermektedir. Fen bilimleri araştırmalarının sonucu genellikle formüle edilmiş bilgi olurken, mühendislik araştırmalarının sonucu ise alternatif tasarımların kapsamlı olarak değerlendirilmesine göre meydana gelen bir ürün olur (Kennedy \& Odell, 2014). $\mathrm{Bu}$ açıdan bakıldığında fen bilimlerinin odağı kanıta dayalı bilgi, mühendisliğin odağı günlük yaşamda kullanılan toplumsal ihtiyaçlar ve istekler doğrultusunda oluşturulan tasarım ve üründür (Taşdemir \& Kaya, 2009). Mühendislik, tıpkı fen bilimlerinde olduğu gibi belirli kurallar çerçevesinde sistematik bir işleyiş sürecine sahiptir (Haik \& Shahin, 2010; NRC, 2012). Fen bilimlerinde bu sistematik işleyiş süreci bireylerin yeterli düzeydeki bilimsel süreç becerilerine gerek duyarken, mühendislikte ise tasarım süreç becerilerine gerek duymaktadır.

Mühendislik tasarım süreci, bir probleme yönelik birden fazla alternatif tasarımın geliştirildiği, üst düzey düşünme becerilerin kullanıldığ 1 , günlük yaşam problemlerine çözümlerin üretildiği ve işbirliği gerektiren bir süreçtir (Marulcu, 2010). Mühendislik tasarım süreci, bir problemin çözümüne yönelik tasarım geliştirme aşamasında başvurulan bir dizi adımlar içerir (Tayal, 2013). Bunlardan en önemlisi geliştirilen tasarımın süreç boyunca öğrenilen yeni bilgiler 1şığında sürekli olarak gözden geçirilmesi ve revize edilmesidir. Mühendislik tasarım sürecinde temel amaç, olası tasarımları değerlendirmek ve geliştirilen alternatif tasarımlar arasından en etkilisini seçmektir (NRC, 2012). Mühendislik tasarım sürecine ilişkin adımlar, Şekil 1'deki modelde gösterilmiştir.

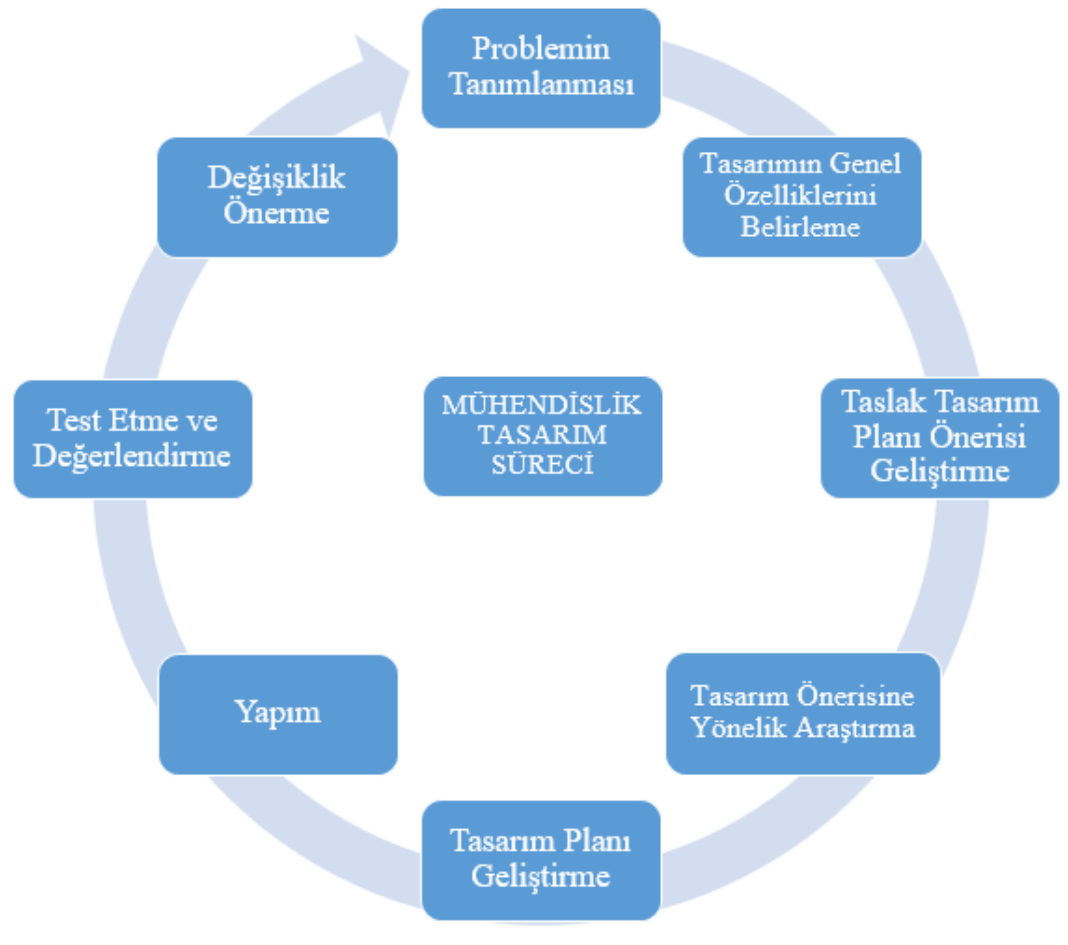

Şekil 1. Mühendislik Tasarım Süreci (NRC, 2012)

Şekil 1'deki modele göre mühendislik tasarım süreci bir döngü halindedir, ancak her zaman daha önceki basamaklara geri dönüş yapılabilir (NRC, 2012). Aşağıda sistematik bir mühendislik tasarım sürecinin temel basamakları özetlenmiştir:

$\checkmark$ Problemin Tanımlanması: Mühendislik tasarım sürecinde öncelikle günlük yaşamdan bir problem belirlenir. Problemin belirlenmesi çok önemlidir. 
$\checkmark$ Tasarımın Genel Özelliklerini Belirleme: Problemi tanımladıktan sonra bazı kriterlerin ve sinırlılıkların belirlenmesinde yarar vardır (NRC, 2012). Tasarımın özellikleri çok dar ya da geniş tutulmamalı, bu durum araştırmacının alternatif çözümler üretmesini kısıtlar ya da hedefinden uzaklaştırabilir (Haik \& Shahin, 2010).

$\checkmark$ Taslak Tasarım Önerisi Geliştirme: Belirlenen özelliklere göre bir taslak tasarım önerisi geliştirilir.

$\checkmark$ Tasarım Önerisine Yönelik Araştırma: Taslak tasarım önerisine yönelik araştırma yapilir.

$\checkmark$ Tasarım Önerisi Geliştirme: Yapılan araştırmalar sonucu taslak tasarım önerisi gözden geçirilir ve düzenlenerek bir tasarım planı geliştirilir.

$\checkmark$ Yapım: Geliştirilen tasarım planına uygun bir şekilde ürün yapılır.

$\checkmark$ Test Etme ve Değerlendirme: Tasarım tamamlandığında ürün test edilir ve değerlendirme aşamasında tasarımın eksik yönleri tespit edilir.

$\checkmark$ Değişiklik Önerme: Tasarımda tespit edilen eksikliklere ve üretilen yeni fikirlere göre tasarımda bazı değişiklikler önerilir ve önerilere göre tasarım tamamlanır (NRC, 2012).

\section{Yöntem}

\subsection{Araştırma Modeli}

$\mathrm{Bu}$ çalışmada deneysel araştırma modellerinden biri olan "ön test-son test denkleştirilmemiş kontrol gruplu yarı deneysel araştırma modeli” benimsenmiştir (Balc1, 2009; Çepni, 2007; Karasar, 1988). Deneysel araştırma modelinin benimsendiği araştırmalarda genellikle bir veya daha fazla kontrol grubu ve deney grubu olarak adlandırılan eşdeğer gruplar belirlenmektedir. Araştırma sürecinde, deney grubuna hipotezin sınandığı özel davranımlar yapılırken, kontrol grubuna ise herhangi bir özel davranımda bulunulmaz. Uygulama öncesinde yapılan ön-test ve uygulama sonrasında yapılan son-testlerle deney grubunda kullanılan özel davranımların deney grubu üzerindeki etkisi araştırılır (Çepni, 2007).

Üzerinde araştırma yapılan bağımlı değişken, öğretmen adaylarının mühendislik tasarım süreç becerileridir. Kontrol ve deney gruplarında kullanılan uygulamalar, çalışmanın bağımsız değişkenleridir. Deney grubunda mobil-FeTeMM öğretim uygulamaları, kontrol grubunda sadece FeTeMM öğretim uygulamaları gerçekleştirilmiştir (Bakınız Tablo 1). Ayrıca, kontrol ve deney grubundaki uygulamalar tek bir eğitimci ile sürdürülmüştür. Deney ve kontrol grubu için ayrıntılı etkinlik uygulamaları "Veri Toplama Süreci" başlığı altında açıklanmıştır. Uygulamanın başında ve sonunda "Mühendislik Tasarım Süreç Becerileri Ölçeği (MTSBÖ)" öğretmen adaylarına uygulanmıştır.

Tablo 1. Çalışmanın Deneysel Deseni

\begin{tabular}{lccc}
\hline \multicolumn{1}{c}{ Grup } & Ön Test & $\begin{array}{c}\text { Öğretim Uygulamaları } \\
(\mathbf{9} \text { Hafta) }\end{array}$ & Son Test \\
\cline { 1 - 1 } Deney grubu & \multirow{2}{*}{ T1: MTSBÖ } & Mobil-FeTeMM & \multirow{2}{*}{ T1: MTSBÖ } \\
\cline { 1 - 1 } Kontrol grubu & & FeTeMM & \\
\hline
\end{tabular}

\section{2. Çalışma Grubu}

Bu çalışmanın katılımcıları Dokuz Eylül Üniversitesi Buca Eğitim Fakültesi Fen Bilgisi Öğretmenliğinin üçüncü sınıf düzeyindeki iki ayrı şubesinde bulunan öğretmen adaylarıdır. Ders döneminin başında yansız atama yöntemine göre bu iki sınıftan biri deney grubu (n: 45) ve diğeri de kontrol grubu (n: 25) olarak belirlenmiştir. Sınıflardaki öğretmen adaylarının sayısı akademik 
yılın dönem başındaki öğretmen adaylarının ders kayıtlarına göre değişkenlik göstermektedir. Ders kayıtları sırasında öğretmen adaylarının alttan ders alma, seçmeli derslerin haftalık ders programında farklı günlerde olması ve ders programlarının çakışması gibi nedenlerle sayıca denk iki sınıfa ulaşılamamaktadır. Dönemin başında her iki gruptaki öğretmen adayları sayıları denk olmasına rağmen dönemin ikinci haftasından sonra deney grubu sayısında belirtilen nedenlerden dolayı bir artış olmuştur. Ayrıca, her iki gruptaki öğretmen adaylarıyla yapılan görüşmelerde iki hafta süren bir FeTeMM öğretim uygulamasına katıldıkları ortaya çıkmıştır. Bu etkinliğe bir önceki akademik yılın güz yarıyılında fizik laboratuvarı dersinde tez kapsamında yaptıklarını, FeTeMM tasarımı olarak sese yalıtımlı en iyi evi modellediklerini ve tasarım sonunda açık uçlu sorularla görüşlerinin alındığını ifade etmişlerdir. Ayrıca bu FeTeMM etkinliğinden başka deneyimlerinin olmadığını açıklamışlardır. Öğretmen adaylarının bu açıklamaları fizik dersi laboratuvarı sorumlusuyla yapılan görüşmelerle teyit edilmiştir. Her iki gruptaki öğretmen adaylarının az da olsa bu FeTeMM öğretim uygulamasıma katılım deneyiminin denk olduğu kabul edilerek çalışmanın verileri toplanmıştır.

\subsection{Veri Toplama Araçları}

Bu çalışmada Moazzen, Miller, Wild, Jackson ve Hadwin (2014) tarafından geliştirilen ve iki bölümden oluşan "Mühendislik Tasarım Anketi”nin ilk bölümü MTSBÖ Türkçeye uyarlanarak kullanılmıştır. 61 maddeden oluşan MTSBÖ 9 alt boyuta ayrılmaktadır. Moazzen ve diğerleri (2014) ölçeğin tamamını öğrencilere verilen mühendislik programı sonrasında görüş alarak geliştirmişler ve ölçeğin alt boyutlarını açımlayıcı faktör analizi yapmadan kendi aralarında fikir birliği ile oluşturmuşlardır. Moazzen ve diğerleri (2014) ölçeği geliştirirken faktör analizi, madde analizi ve güvenirlik hesaplamaları yapmamıştır. Ölçek ilk olarak dörtlü Likert tipi özelliğine göre geliştirilmiştir. Araştırmacılar sonraki çalışmalarda ölçeğin beşli Likert tipiyle denenmesini önermiştir. Bu nedenle bu çalışmada beşli Likert olarak kullanılmıştır. Ölçek, 5'li Likert (Çok Kolay (5), Kolay (4), Orta (3), Zor (2), Çok Zor (1)) tipindedir. Bu çalışma için ölçeğin betimsel, yapı, geçerlik ve güvenirlik analizleri gerçekleştirilmiştir.

Ölçeğin dil geçerliği uzmanlarla yapılan görüşmelerle sağlanmıştır. Ölçek ilk olarak dil uzmanı (Dokuz Eylül Üniversitesi İngilizce öğretmenliği programında görevli bir öğretim üyesi) tarafından Türkçeye çevrilmiştir. Türkçeye çevrilmiş ölçek başka bir dil uzmanı (Akademik dil puanı yüksek olan ve fen bilgisi öğretmenliği programında görevli öğretim üyesi) tarafindan tekrar İngilizce diline çevrilmiştir. Ölçeğin orijinal İngilizcedeki dil yapısı ile Türkçeden İngilizceye çevrilmiş dil yapısı karşılaştırılmıştır. Uyum sağlamayan test maddeleri Dokuz Eylül Üniversitesi fen bilgisi öğretmenliği programında görevli iki öğretim üyesi tarafından incelenerek Türkçeye uygun test maddesi için gerekli düzenlemeler yapılmıştır. Test maddelerinin nihai hali alan uzmanlarıyla değerlendirilerek öğretmen adaylarına uygulanmak üzere hazırlanmıştır. Güvenilirlik analizi için her bir maddenin madde-toplam korelasyonları dikkate alınmış; ölçeğin boyutları yapı geçerliği için doğrulayıcı faktör analizi yapılmış, ölçeğin ve alt boyutlarının Cronbach Alpha güvenirlik katsayıları hesaplanmıştır.

İlk olarak Tablo 2'de MTSBÖ ile ilgili maddelerin madde-toplam korelasyonlarına ilişkin bulgular verilmişsir. 
Mobil-FeTeMM Öğretim Uygulamalarının Öğretmen Adaylarının Mühendislik Tasarım Süreç Becerilerine Etkisi

Tablo 2. Ölçekteki Maddelerin Madde-Toplam Korelasyonlarına İlişkin Bulgular

\begin{tabular}{cccccccccccc}
\hline Madde & $\overline{\mathbf{x}}$ & $\boldsymbol{\sigma}$ & $\mathbf{r}_{\mathbf{x y}}$ & $\mathbf{M a d d e}$ & $\overline{\mathbf{x}}$ & $\boldsymbol{\sigma}$ & $\mathbf{r}_{\mathbf{x y}}$ & Madde & $\overline{\mathbf{x}}$ & $\boldsymbol{\sigma}$ & $\mathbf{r}_{\mathbf{x y}}$ \\
\hline 1 & 2,82 & 0,858 & $0,329^{*}$ & 21 & 3,04 & 0,923 & $0,553^{*}$ & 41 & 2,80 & 0,892 & $0,626^{*}$ \\
\hline 2 & 2,68 & 0,792 & $0,472^{*}$ & 22 & 3,34 & 0,982 & $0,392^{*}$ & 42 & 2,89 & 0,782 & $0,519^{*}$ \\
\hline 3 & 2,72 & 0,830 & $0,551^{*}$ & 23 & 2,69 & 1,040 & $0,341^{*}$ & 43 & 2,85 & 0,866 & $0,629^{*}$ \\
\hline 4 & 2,66 & 0,886 & $0,585^{*}$ & 24 & 2,92 & 0,856 & $0,512^{*}$ & 44 & 2,92 & 0,849 & $0,603^{*}$ \\
\hline 5 & 2,73 & 0,863 & $0,558^{*}$ & 25 & 2,83 & 0,876 & $0,604^{*}$ & 45 & 2,85 & 0,918 & $0,550^{*}$ \\
\hline 6 & 2,88 & 0,809 & $0,494^{*}$ & 26 & 2,84 & 1,052 & $0,519^{*}$ & 46 & 2,93 & 0,830 & $0,568^{*}$ \\
\hline 7 & 3,06 & 0,969 & $0,328^{*}$ & 27 & 2,75 & 0,748 & $0,593^{*}$ & 47 & 2,54 & 0,803 & $0,631^{*}$ \\
\hline 8 & 2,59 & 0,978 & $0,514^{*}$ & 28 & 3,00 & 0,874 & $0,591^{*}$ & 48 & 2,94 & 0,854 & $0,540^{*}$ \\
\hline 9 & 2,87 & 0,931 & $0,343^{*}$ & 29 & 3,08 & 0,968 & $0,353^{*}$ & 49 & 2,88 & 0,898 & $0,617^{*}$ \\
\hline 10 & 2,42 & 0,897 & $0,559^{*}$ & 30 & 2,89 & 0,790 & $0,537^{*}$ & 50 & 2,93 & 0,952 & $0,601^{*}$ \\
\hline 11 & 2,30 & 1,020 & $0,406^{*}$ & 31 & 2,75 & 0,842 & $0,486^{*}$ & 51 & 2,80 & 0,753 & $0,541^{*}$ \\
\hline 12 & 2,18 & 0,957 & $0,625^{*}$ & 32 & 2,75 & 0,798 & $0,596^{*}$ & 52 & 2,49 & 1,144 & $0,447^{*}$ \\
\hline 13 & 2,56 & 0,809 & $0,549^{*}$ & 33 & 2,82 & 0,770 & $0,547^{*}$ & 53 & 2,34 & 0,969 & $0,568^{*}$ \\
\hline 14 & 2,59 & 0,822 & $0,588^{*}$ & 34 & 2,67 & 0,892 & $0,606^{*}$ & 54 & 2,38 & 0,981 & $0,573^{*}$ \\
\hline 15 & 2,76 & 0,870 & $0,580^{*}$ & 35 & 2,41 & 0,890 & $0,545^{*}$ & 55 & 2,22 & 0,980 & $0,493^{*}$ \\
\hline 16 & 2,32 & 0,945 & $0,473^{*}$ & 36 & 2,90 & 1,023 & $0,461^{*}$ & 56 & 2,46 & 1,001 & $0,609^{*}$ \\
\hline 17 & 2,65 & 0,874 & $0,591^{*}$ & 37 & 2,56 & 0,856 & $0,557^{*}$ & 57 & 2,41 & 0,932 & $0,623^{*}$ \\
\hline 18 & 2,80 & 0,858 & $0,686^{*}$ & 38 & 2,78 & 0,988 & $0,478^{*}$ & 58 & 2,46 & 1,092 & $0,600^{*}$ \\
\hline 19 & 2,67 & 0,980 & $0,485^{*}$ & 39 & 2,97 & 0,917 & $0,438^{*}$ & 59 & 2,37 & 0,973 & $0,637^{*}$ \\
\hline 20 & 2,64 & 0,897 & $0,491^{*}$ & 40 & 3,51 & 1,069 & $0,392^{*}$ & 60 & 2,26 & 0,952 & $0,636^{*}$ \\
\hline & & & & & & & & 61 & 2,41 & 1,016 & $0,547^{*}$ \\
\hline
\end{tabular}

*p $<0,05$ olduğu için sonuçlar istatistiksel olarak anlamlıdır

$\overline{\mathrm{x}}$ : ortalama, $\sigma$ : standart sapma, $\mathrm{r}_{\mathrm{xy}}$ : Madde Toplam Korelasyonu

Tablo 2'deki bu sonuçlara göre madde-toplam korelasyon değerleri $\mathrm{r}_{\mathrm{xy}}=0,328(\mathrm{~m} 7)$ ile $\mathrm{r}_{\mathrm{xy}}=0,686$ (m18) arasında değişmektedir. Tablo 2'de madde-korelasyon değerleri incelendiğinde ölçeğin geneliyle ölçülebilecek özelliğin her bir madde ile ölçülmeye çalışılan özellikle benzer olduğu ve ölçekteki tüm maddelerin öğretmen adaylarına uygulanmak üzere kullanılabileceğine karar verilmiştir.

İkinci olarak ölçeğin yapı geçerliğinin çalışmanın örnekleminde doğrulanıp doğrulanmadığının incelenmesi amacıyla doğrulayıc1 faktör analizi (DFA) gerçekleștirilmiştir. DFA, AMOS 16 programında en yüksek olabilirlik yöntemiyle (Maximum Likelihood) gerçekleştirilmiştir. Faktöriyel yapının gözlemlenen değerlerle uyum derecesinin belirlenebilmesi amacıyla $\mathrm{CMIN} / \mathrm{df}<5$, RMSEA $<0,08$ ve $\mathrm{RMR}<0,08$ uyum indekslerinin değerleri kullanılmıștır (Çokluk, Şekercioğlu \& Büyüköztürk, 2012; Kline, 2011). DFA sonucunda 61 maddelik MTSBÖ’nün 9 faktörlü DFA modeli CMIN/DF=1,713; RMSEA=0,055; RMR=0,062 uyum indekslerine göre kabul edilen uyum indeksinin üstünde olduğundan iyi düzeyde bir uyum gösterdiği, $\mathrm{CFI}=0,840$; GFI $=0,702$; AGFI $=0,672$ uyum indekslerine göre ise kabul edilen uyum indeksinin altında kaldığından kötü düzeyde bir uyum gösterdiği görülmüştür (Erkorkmaz, Etikan, Demir, Özdamar \& Sanisoğlu, 2013).

Son olarak Tablo 3'de MTSBÖ'nün alt boyutlarına ilişkin örnek ölçek maddeleri, faktör yükleri ve güvenirlik katsayıları gibi ölçek yapısıyla ilgili bilgiler verilmiştir. 
Tablo 3. MTSBÖ’nün Alt Boyutlarına İlişkin Ölçek Yapı Bilgileri

\begin{tabular}{|c|c|c|c|c|}
\hline $\begin{array}{l}\text { Alt Boyutlar } \\
\text { (Madde Sayısı) }\end{array}$ & $\begin{array}{c}\text { Ölçek } \\
\text { Madde } \\
\text { Numaraları } \\
\end{array}$ & $\begin{array}{c}\text { Faktör Yük } \\
\text { Aralığı }\end{array}$ & $\begin{array}{l}\text { Cronbach } \\
\text { Alpha }\end{array}$ & Örnek Ölçek Maddeleri \\
\hline $\begin{array}{l}\text { Hedefleri } \\
\text { Belirleme (6) }\end{array}$ & $1,2,3,4,5,6$ & $0,545-0,686$ & 0,795 & $\begin{array}{l}\text { Tasarımın beklentileri ne kadar karşıladığına karar } \\
\text { vermek için ölçülebilir hedefler belirlemek } \\
\text { Tasarım hedeflerinin gereksinimlerle uyumlu } \\
\text { olmasını sağlamak }\end{array}$ \\
\hline Plan Yapma (6)) & $\begin{array}{l}7,8,9,10 \\
11,12\end{array}$ & $0,406-0,698$ & 0,778 & $\begin{array}{l}\text { Tasarımı tamamlamak için gerekli işleri } \\
\text { belirlemek } \\
\text { Her bir işin ne kadar süreceğini tespit etmek }\end{array}$ \\
\hline Bilgi Toplama (8) & $\begin{array}{l}13,14,15 \\
16,17,18 \\
19,20\end{array}$ & $0,527-0,619$ & 0,848 & $\begin{array}{l}\text { Tasarım etkinliklerini gerçekleştirmek için } \\
\text { gereken bilgileri tespit etmek } \\
\text { Gerekli bilgiler için uygun bilgi kaynakları tespit } \\
\text { etmek }\end{array}$ \\
\hline $\begin{array}{l}\text { Alternatif Tasarım } \\
\text { Üretme (6) } \\
\end{array}$ & $\begin{array}{l}21,22,23 \\
24,25,26\end{array}$ & $0,504-0,655$ & 0,764 & $\begin{array}{l}\text { Tasarım için alternatif çözümler üretmek } \\
\text { Fikir üretmek için etkili teknikler kullanmak }\end{array}$ \\
\hline $\begin{array}{l}\text { Alternatif Tasarım } \\
\text { Seçme (9) }\end{array}$ & $\begin{array}{l}27,28,29 \\
30,31,32 \\
33,34,35\end{array}$ & $0,461-0,662$ & 0,826 & $\begin{array}{l}\text { Alternatif çözümleri değerlendirmek için uygun } \\
\text { kriterler belirlemek } \\
\text { Karar verme için uygun verileri tam olarak } \\
\text { değerlendirmek }\end{array}$ \\
\hline Modelleme (8) & $\begin{array}{l}36,37,38 \\
39,40,41 \\
42,43\end{array}$ & $0,494-0,720$ & 0,820 & $\begin{array}{l}\text { Tasarımın parçaları arasındaki ilişkileri tespit } \\
\text { etmek Modelleme için bilgisayarda çizim } \\
\text { yazılımları kullanmak }\end{array}$ \\
\hline $\begin{array}{l}\text { Tasarım Revizyon } \\
\text { (8) }\end{array}$ & $\begin{array}{l}44,45,46 \\
47,48,49 \\
50,51\end{array}$ & $0,418-0,734$ & 0,888 & $\begin{array}{l}\text { Gerektiğinde problem tanımını revize etmek veya } \\
\text { değiştirmek } \\
\text { Tasarım hedeflerini ve sınırlarını gerektiğinde } \\
\text { revize etmek veya değiştirmek }\end{array}$ \\
\hline Raporlama (4) & $52,53,54,55$ & $0,466-0,699$ & 0,853 & $\begin{array}{l}\text { Tasarım raporunu açık ve anlaşılır bir şekilde } \\
\text { yazmak } \\
\text { Sunumdan önce raporu dikkatlice okumak }\end{array}$ \\
\hline Sunum (6) & $\begin{array}{l}56,57,58 \\
59,60,61\end{array}$ & $0,634-0,757$ & 0,929 & $\begin{array}{l}\text { Sunumu dinleyici seviyesinde uygun hale getirmek } \\
\text { Sunumda gerektikçe çizimler veya şekiller } \\
\text { kullanmak }\end{array}$ \\
\hline
\end{tabular}

Tablo 3'de en düşük Chronbach Alpha güvenirlik katsayısı "Alternatif Tasarım Üretme" alt boyutunda $(0,764)$, en yüksek Chronbach Alpha güvenirlik katsayıs1 ise "Sunum" alt boyutundadır $(0,929)$. Ölçeğin genelinin Chronbach Alpha güvenirlik katsayısı 0,960'dır. En düşük madde sayısı "Raporlama" alt boyutunda (4 madde), en fazla madde sayısı "Alternatif Tasarım Seçme" alt boyutundadır (9 madde). En düşük faktör yükü "Plan Yapma" alt boyutunda $(0,406)$, en yüksek faktör yükü "Sunum" alt boyutundadır (0,757). 9 alt boyutlu 61 maddelik ölçme aracının açıkladığı toplam varyans oranı ise \%61,24'dür.

Tablo 4. Ölçek Alt Boyutlarının Kendi Aralarındaki Korelasyon Değerleri

\begin{tabular}{|c|c|c|c|c|c|c|c|c|}
\hline Ölçeğin Alt Boyutları & 2 & 3 & 4 & 5 & 6 & 7 & 8 & 9 \\
\hline 1. Hedefleri Belirleme & $0,577^{*}$ & $0,528^{*}$ & $0,498^{*}$ & $0,588^{*}$ & $0,495^{*}$ & $0,554^{*}$ & $0,451^{*}$ & $0,453^{*}$ \\
\hline 2. Plan Yapma & 1 & $0,581^{*}$ & $0,478^{*}$ & $0,531^{*}$ & $0,350^{*}$ & $0,497^{*}$ & $0,421^{*}$ & $0,453^{*}$ \\
\hline 3. Bilgi Toplama & & 1 & $0,615^{*}$ & $0,697^{*}$ & $0,533^{*}$ & $0,617^{*}$ & $0,435^{*}$ & $0,531^{*}$ \\
\hline 4. Alternatif Tasarım Üretme & & & 1 & $0,689^{*}$ & $0,512^{*}$ & $0,632^{*}$ & $0,265^{*}$ & $0,385^{*}$ \\
\hline 5. Alternatif Tasarım Seçme & & & & 1 & $0,632^{*}$ & $0,715^{*}$ & $0,399^{*}$ & $0,506^{*}$ \\
\hline 6. Modelleme & & & & & 1 & $0,579^{*}$ & $0,427^{*}$ & $0,473^{*}$ \\
\hline 7. Tasarım Revizyon & & & & & & 1 & $0,381^{*}$ & $0,424^{*}$ \\
\hline 8. Raporlama & & & & & & & 1 & $0,736^{*}$ \\
\hline 9. Sunum & & & & & & & & 1 \\
\hline
\end{tabular}


Mobil-FeTeMM Öğretim Uygulamalarının Öğretmen Adaylarının Mühendislik Tasarım Süreç Becerilerine Etkisi

Tablo 4'de MTSBÖ ile ilgili alt boyutlarına ilişkin korelasyon değerleri verilmiştir. Bu değerlere bakıldığında ölçeğin alt boyutları arasında pozitif korelasyon görülmektedir. Bu değerler ölçeğin mühendislik tasarım süreç becerileriyle ilgili alt boyutların yapısal bütünlüğünün olduğunu göstermektedir.

Bir ölçeğin güvenilir olarak kabul edilebilmesi için Cronbach alfa katsayısının 0,70'den büyük olması gerekir (Büyüköztürk, Çakmak, Akgün, Karadeniz \& Demirel, 2014). Diğer yandan 0,610,80 aralığındaki değerlerin orta düzeyde, 0,81-1,00 aralığındaki değerlerin ise yüksek güvenilirliğe işaret ettiği belirtilmektedir (Özdamar, 2002; Tabachnick \& Fidell, 2001). Sonuç olarak bu bulgular, söz konusu ölçeğin yapı geçerlikleriyle iç tutarlılık katsayılarının ve güvenirliklerinin, bu çalışmanın örneklemi kapsamında tatmin edici olduğunu göstermektedir.

\subsection{Veri Toplama Süreci}

Çalışmaya katılan öğretmen adaylarının kayıtlı oldukları mevcut sınıfları seçkisiz olarak deney ve kontrol grubu olarak belirlenmiş, her iki gruba da ön-testler doldurmaları için verilmiştir. Öğretmen adayları toplam 9 hafta süren üç FeTeMM tasarımı gerçekleştirmiştir. Tüm FeTeMM tasarımları bittikten sonra dönem sonunda öğretmen adaylarına ön testte dağıtılan aynı test son test olarak dağıtılmıştır.

\subsection{Uygulama Süreci}

Fen Laboratuvar Uygulamaları dersinin haftalık 4 saatinin 2 saati FeTeMM ögretim uygulamalarına ayrılmıştır. Her FeTeMM tasarımı için 3 hafta boyunca toplam 6 saat uygulama saati verilmiştir. Her FeTeMM öğretim uygulaması sürecinde tasarımlar başlamadan önce ilk hafta her iki gruba teorik bilgi anlatılmıştır. Tasarımlardan önce FeTeMM etkinliğinde gerekli ölçme işlemleri için basit bir fen etkinliği üzerinden deney grubundaki öğretmen adayları mobil cihazlarla ölçme işlemi, kontrol grubundaki öğretmen adayları laboratuvarda kullanılan cihazlarla bir ölçme işlemi gerçekleştirmiştir. Öğretmen adaylarının tasarımlarında gerekli ölçme işlemlerini yapabilmeleri için tasarım öncesi mobil cihazlarla ve gerekli laboratuvar ölçme araçlarıyla ölçme becerilerini geliştirme etkinlikleri yaptırılmıştır. Daha sonra her iki gruba da bir senaryo verilmiştir ve 1 hafta sonrasına konuyla ilgili FeTeMM öğretim modeline uygun bir tasarım ortaya koymaları istenmiştir. Öğretmen adaylarının FeTeMM tasarımının hedefine ulaşıp ulaşmadığını anlamaları için tasarımdan önce öğrendikleri ölçme işlemlerini tasarımlarında kullanmaları gerektiği söylenmiştir. Bir hafta sonra FeTeMM tasarımları incelenerek öğretmen adaylarına geliştirmesi için tavsiyelerde bulunulmuş, tasarımlarını geliştirmeleri için 1 hafta daha süre verilmiş ve tasarımlarını raporlamaları istenmiştir. FeTeMM tasarım uygulamaları toplam 9 hafta sürdürülmüştür.

Örnek Bir FeTeMM Etkinliğinin Uygulama Süreci: Bu etkinlikte öğretmen adaylarına 3 hafta süren bir Rüzgâr Türbini tasarlatılmıştır. İlk haftada öğretmen adaylarının hatırlaması için Rüzgâr Türbiniyle ilişkili tüm kavramların teorik bilgisi anlatılmıştır. İkinci haftada Rüzgâr Türbini tasarımından önce bir basit elektrik devresinde akım şiddetinin değişimine göre lambaların parlaklığının ölçüldüğü bir deney gerçekleştirilmiştir. Bu deneyde lambaların parlaklığı deney grubunda akı1lı telefonların 1şık şiddetini ölçen uygulamayla, kontrol grubunda voltmetre ve ampermetreyle dolaylı olarak ölçülmüştür. Üçüncü haftada öğretmen adaylarına Rüzgâr Türbini laboratuvar ortamında tasarlatılmış ve ikinci haftada öğrenilen ölçme becerilerine göre Rüzgar Türbininin hızı ve devir sayısı hesaplatılmıştır. Öğretmen adaylarının Rüzgâr Türbinine yönelik tasarımlarına gerekli dönütler verilmiş, tasarımlarını iyileştirerek bir hafta sonra göstermeleri ve raporlarını vermeleri istenmiştir. 


\subsection{Verilerin Analizi}

Öğretmen adaylarının MTSBÖ'den aldıkları puanlarının normal dağılımları KolmogorovSmirnov ve Shapiro-Wilk testleriyle incelenmiştir. Bu MTSBÖ'nün toplamında ve alt boyutlarında hesaplanan puanların normallik dağılımını sağlamadığı ve kontrol grubunun katılımcı sayısı 30 kişiden az olduğu için veriler parametrik olmayan testlerden Mann-Whitney U (MWU) testi ile analiz edilmiştir.

Deney ve kontrol grubu arasındaki karşılaştırmalarda, MWU testinin p değeri 0,05'ten küçükse, test sonucunun istatistiksel olarak anlamlı olduğu ve iki grup arasında anlamlı bir fark olduğu varsayılmıştır. Alternatif olarak, bu test sonuçlarının istatistiksel anlamlılığını desteklemek için, MWU testinin etki büyüklükleri aşağıdaki formülle hesaplanmıştır: (Tomczak \& Tomczak, 2014).

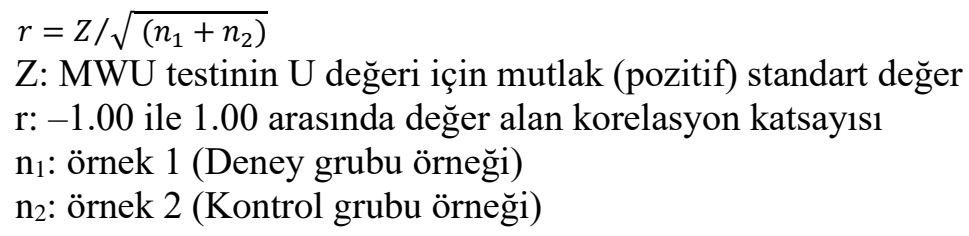

Deney ve kontrol grubu arasındaki karşılaştırmalar yorumlanırken etki büyüklükleri Cohen'in (1992) taksonomisine göre 0,10-0,29 aras1 değerler "Küçük Etki”, "0,30-0,49" aras1 değerler “Orta Etki” ve 0,5'den büyük değerler "Büyük Etki” olarak sınıflandırılmıştır.

\subsection{Etik Kurul İzin}

Yapılan bu çalışmada "Yükseköğretim Kurumları Bilimsel Araştırma ve Yayın Etiği Yönergesi" kapsamında uyulması belirtilen tüm kurallara uyulmuştur. Bu çalışma için etik kurul izni Dokuz Eylül Üniversitesi Eğitim Bilimleri Enstitüsü Etik Kurulu'nun 23.11.2017 tarihli ve 12 numaralı kararı ile alınmıştır.

\section{Bulgular}

MTSBÖ'nün toplam ve alt boyutlarına ilişkin ön test puanları deney ve kontrol grupları arasında MWU testi ile analiz edilmiş ve 0,05 anlamlılık düzeyinde istatistiksel olaral bir farklılık bulunamamıştır. $\mathrm{Bu}$ durumda deneysel uygulamadan önce deney ve kontrol grubunun MTSBÖ'nün toplam ve alt boyutlarına göre mühendislik tasarım becerilerinin denk olduğu anlaşılmıştır. Böylelikle çalışmada deneysel uygulamanın etkisini görmek için MTSBÖ’nün toplam son test ve ön test fark puanları MWU testi ile analiz edilmiştir. Tablo 5'de MTSBÖ'nün toplam son test ve ön test fark puanlarına göre deney ve kontrol grubunun karşılaştırıldığ $\mathrm{MWU}$ testi analiz sonuçları verilmiştir.

Tablo 5. MTSBÖ Son Test ve Ön Test Fark Puanı MWU Testi Analiz Sonuçları

\begin{tabular}{lccccc}
\hline \multicolumn{1}{c}{ Şube } & Sira Ortalaması & MWU & $\mathbf{Z}$ & $\begin{array}{c}\text { Etki } \\
\text { Büyüklüğ̈̈ (r) }\end{array}$ & $\mathbf{p}$ \\
\hline Deney & 31,71 & 392,0 & $-2,091$ & $\begin{array}{c}0,250 \\
\text { (Orta Etki) }\end{array}$ & $0,037^{*}$ \\
\cline { 1 - 2 } Kontrol & 42,32 & & MWU testinin p değeri 0,05 'ten kü̧̧ük ise test sonucu istatistiksel olarak anlamlıdır ve iki grup arasında anlamlı fark vardır.
\end{tabular}

Tablo 5'de MWU testi analiz sonucu deney ve kontrol grubu arasında MTSBÖ toplam son test ve ön test fark puanlarının kontrol grubu lehine anlamlı olduğunu göstermektedir (U=392,0, $\mathrm{p}=0,037)$. Bu sonuçlara göre deney grubunda mobil-FeTeMM öğretim uygulamaları ile etkinlik 
Mobil-FeTeMM Öğretim Uygulamalarının Öğretmen Adaylarının Mühendislik Tasarım Süreç Becerilerine Etkisi

tasarlayan öğretmen adaylarının mühendislik tasarım süreç becerilerinin kontrol grubuna göre gelişimi daha azdır. Genel olarak mobil-FeTeMM öğretim uygulamalarının kontrol grubuna kıyasla deney grubundaki öğretmen adaylarının mühendislik tasarım süreç becerilerini az etkilemiştir.

Tablo 6. MTSBÖ Alt Boyutları Son Test ve Ön Test Fark Puanı MWU Testi Analiz Sonuçları

\begin{tabular}{lcccccc}
\hline \multirow{2}{*}{$\begin{array}{c}\text { MTSBÖ'nün Alt } \\
\text { Boyutları }\end{array}$} & \multicolumn{2}{c}{$\begin{array}{c}\text { Sira Ortalaması } \\
\text { (Gruplar) }\end{array}$} & \multirow{2}{*}{ MWU } & $\mathbf{Z}$ & \multirow{2}{*}{ Etki Büyüklüğü (r) } & p \\
\cline { 2 - 6 } & Deney & Kontrol & & & & \\
\hline Hedefleri Belirleme & 31,01 & 43,58 & 360,5 & $-2,494$ & 0,298 (Orta Etki) & $0,013^{*}$ \\
\hline Plan Yapma & 28,89 & 47,40 & 265,0 & $-3,667$ & 0,438 (Büyük Etki) & $0,000^{*}$ \\
\hline Bilgi Toplama & 28,61 & 47,90 & 252,5 & $-3,812$ & 0,456 (Büyük Etki) & $0,000^{*}$ \\
\hline Alternatif Tasarım Üretme & 31,56 & 42,60 & 385,0 & $-2,189$ & 0,262 (Küçük Etki) & $0,029^{*}$ \\
\hline Alternatif Tasarım Seçme & 35,09 & 36,24 & 544,0 & $-0,228$ & 0,027 (Etki yok) & 0,820 \\
\hline Modelleme & 36,09 & 34,44 & 536,0 & $-0,326$ & 0,039 (Etki yok) & 0,744 \\
\hline Tasarım Revizyon & 33,37 & 39,34 & 466,5 & $-1,180$ & 0,141 (Küçük Etki) & 0,238 \\
\hline Raporlama & 33,13 & 39,76 & 456,0 & $-1,317$ & 0,157 (Küçük Etki) & 0,188 \\
\hline Sunum & 35,70 & 35,14 & 553,5 & $-0,111$ & 0,013 (Etki Yok) & 0,912 \\
\hline
\end{tabular}

* MWU testinin p değeri 0,05'ten küçük ise test sonucu istatistiksel olarak anlamlıdır ve iki grup arasında anlamlı fark vardır.

Tablo 6'da MTSBÖ’nün "Hedefleri Belirleme" (U=360,5, p=0,013), "Plan Yapma” (U=265,0, $\mathrm{p}=0,000)$, "Bilgi Toplama" ( $\mathrm{U}=252,5, \mathrm{p}=0,000)$ ve "Alternatif Tasarım Üretme" (U=385,0, $\mathrm{p}=0,029)$ " alt boyutlarına ilişkin MWU testi analiz sonuçları kontrol grubu lehine istatistiksel olarak anlamlı fark olduğunu göstermektedir. MWU testi analiz sonuçları istatistiksel olarak anlamlı olan alt boyutların genel olarak sıra ortalamalarına kabaca bakıldığında deney grubundaki öğretmen adaylarının mobil-FeTeMM öğretim uygulamalarıyla etkinlik tasarlarken MTSBÖ'nün "Hedef Belirleme", "Plan Yapma", "Bilgi Toplama" ve "Alternatif Tasarım Üretme" alt boyutlarında daha az ilerleme olduğu görülmüştür. MTSBÖ’nün “Alternatif Tasarımları Seçme”, "Model Oluşturma", "Tasarımı Revize Etme", "Raporlama" ve "Sunum" alt boyutlarındaki değişim her iki grupta da benzerdir ve gruplar arasında anlamlı bir farklılık yoktur. Yine aynı şekilde MWU testi analiz sonuçları istatistiksel olarak anlamlı olamayan alt boyutların genel olarak sıra ortalamalarına kabaca bakıldığında MTSBÖ'nün "Alternatif Tasarım Seçme”, "Modelleme", "Tasarım Revizyon", "Raporlama" ve "Sunum Yapma" alt boyutlarında deney grubunun kontrol grubuyla aynı becerileri sergilediği anlaşılmıştır.

\section{Tartışma ve Sonuçlar}

$\mathrm{Bu}$ çalışmada, mobil-FeTeMM öğretim uygulamalarının öğretmen adaylarının mühendislik tasarım süreç becerilerine etkisi incelenmiştir. $\mathrm{Bu}$ amaçla öğretmen adaylarının mühendislik tasarım süreç becerileri, 61 maddelik MTSBÖ ile ölçülmüştür. Deney ve kontrol grubu arasında MTSBÖ'nün toplam ve alt boyutlarına ilişkin son test ve ön test fark puanlarına göre MWU testi analizleri yapılmış ve kontrol grubu lehine bazı sonuçlara ulaşılmıştır.

Çalışma sonuçları deney grubundaki öğretmen adaylarının MTSBÖ'nün toplam son test ve ön test fark puanlarının kontrol grubundaki öğretmen adaylarının puanlarına göre daha az olduğunu ve istatistiksel olarak kontrol grubunun lehine anlamlı değiştiğini göstermiştir. Çalışmaya genel olarak bakıldığında beklenen tahminlerin dışında bir sonuçla karşılaşılmış, deney grubunda FeTeMM öğretim uygulamalarına mobil teknolojinin entegre edilmesinin MTSBÖ'nün mühendislik tasarım süreç becerilerini olumlu yönde geliştirmediği görülmüştür. Ayrıca deney grubundaki öğretmen adaylarının MTSBÖ'nün hedefleri belirleme, plan yapma, bilgi toplama ve alternatif tasarım üretme alt boyutlarındaki mühendislik tasarım süreci becerileri gelişimleri 
kontrol grubuna göre daha az olmuştur. Bu çalışmaya benzer biçimde Bozkurt ve Özyurt (2019) bir FeTeMM öğretim uygulamalarından sonra öğretmen adaylarıyla yaptığı görüşmelerde FeTeMM öğretim uygulamalarının ön hazırlık ve planlama aşamasının sorunlu olduğunu, zaman aldığını, grup işbirliğini zor sağlandığını ve malzeme tedariğinde sıkıntılar yaşandığını ortaya koymuştur. Mentzer ve diğerleri (2015), mühendislik eğitimi almayan birincisi sınıf lise öğrencileri ile mühendislik eğitimi alan son sınıf lise öğrencilerinin tasarım sürecindeki farklılıklarını incelediği çalışmada birinci sınıf lise öğrencilerinin problem belirleme ve bilgi toplama sürecine yeterince zaman ayırmadığını, ayrıca bu öğrencilerin ilk düşündükleri çözüme (tasarıma) çok fazla bağlandıkları ve bu durumun alternatif tasarım geliştirmelerine engel olduğunu ifade etmişlerdir. Benzer şekilde English ve diğerleri (2017) altıncı sınıf öğrencileriyle depreme dayanıklı binalarla ilgili FeTeMM etkinlik çalışmasında, öğrencilerin ilk tasarımlarını revize etmekte zorlandığı ve tasarımlarını geliştiremediği görülmüştür. Altan, Yamak ve Kırıkkaya (2016) yaptıkları çalışmada öğrencilere FeTeMM öğretimini yansıtabilmek için tasarım temelli fen öğretimi vererek öğretmen adaylarının bu süreçte alternatif tasarımların geliştirilmesinde, alternatif tasarımın seçilmesinde ve tasarımın yapılmasında zorluk yaşadıklarını tespit etmişlerdir. Bazı çalışmalarda mobil teknolojilerin FeTeMM ve laboratuvar uygulamalarına yönelik entegrasyonun başında zorlanmalar olabileceği; ancak iyi planlamayla bu entegrasyonun gerçekleşebileceği ifade edilmiştir. Örneğin Okur (2021) yaptığ ç̧alışmada fen bilgisi öğretmen adaylarının laboratuvar ortamında mobil teknolojilerini kullanmada ilk başta zorlandıklarını ve daha sonra sürece alıştıklarını gözlemlemiştir. Benzer şekilde Nithia ve diğerleri (2015), mobil öğrenme teknolojileri iyi bir şekilde planlanır ve uygulanırsa, FeTeMM uygulamalarında öğrenci performanslarının artabileceğini belirtmiştir. Bu çalışmanın bulgularının aksine ve bazı çalışma sonuçlarından farklı olarak bazı araştırmalar FeTeMM öğretiminde mobil teknoloji kullanmanın faydalarını ortaya koymuştur. Örneğin Tantu (2017) yaptığı çalışmada, FeTeMM öğretiminde mobil teknoloji kullanmanın FeTeMM öğretimine olumlu etkisi olduğunu ortaya koymuştur. Delen ve Uzun (2018), farklı branşların FeTeMM öğretim modeline uygun tasarımları nasıl tasarlayacağını tespit etmek amacıyla Fen-Teknoloji ve Toplum dersi kapsamında matematik öğretmen adaylarıyla yaptığı çalışmada öğretmen adayları mühendislik tasarımı geliştirmişlerdir ve öğretmen adaylarının teknolojiyi matematik ve fene entegre etmede değil, buradan yola çıkarak tasarım üretmede zorlandıklarını belirtmişlerdir. Yapılan çalışmalar incelendiğinde FeTeMM öğretim uygulamalarının en zorlayıcı kısmın tasarım aşamalarının ön hazırlık, planlama, bilgi toplama, alternatif tasarım üretme gibi süreçlerin olduğu görülmektedir. Bu çalışmanın sonuçları ve bazı araştırma bulguları FeTeMM öğretim modeline mobil teknolojinin entegrasyonu için uzun bir sürecin olduğunu göstermektedir. Ancak teknolojinin gelişimiyle birlikte öğrencilerin, öğretmenlerin ve öğretmen adaylarının bu teknolojilere yönelik deneyimlerine paralel olarak modelin uygulanabilir hale gelebileceği de düşünülmektedir.

FeTeMM'in bileşenlerinden teknoloji boyutu uygulamalarda ve tasarımlarda problemli bir boyut olarak görünmektedir. Deney grubundaki öğretmen adaylarının mühendislik tasarım becerilerinin kontrol grubuna göre düşük olmasının sebebi, deney grubundaki öğretmen adaylarının mobil teknolojileri ilk defa kullanmaları ve mobil öğrenme teknolojilerini (mobil cihazlar ve sensörler) bir FeTeMM etkinliğine uyarlamada zorlanmaları olabilir. Hiğde, Keleş ve Aktamış (2020) yaptıkları çalışmada öğretmenlerin FeTeMM'i sınıflarında uygulamaya yönelik özgüvenleriyle FeTeMM'in Fen, Teknoloji, Mühendislik ve Matematik alt alanları arasında bir path analizini çıkarmıştır. Bu analize göre öğretmenlerin FeTeMM'in teknoloji alt alanı hariç diğer alanlarıyla iyi uyumlu bir ilişkinin olduğu tespit edilmiştir. Hiğde ve diğerlerinin (2020) çalışmalarındaki FeTeMM'in teknoloji alt boyutunun diğer alt boyutlarla path analizine göre uyumsuzluğu bu çalışmanın mobil teknoloji boyutunda yaşanan sorunu doğrular niteliktedir. FeTeMM araştırmacıları ve FeTeMM öğretim modelini kullanan öğretmenler öğretim sürecinde başarılı olabilmeleri için bu öğretim modelinin teknoloji boyutuna odaklanmalı ve çözümlerini bu noktada üretmelidirler. Mobil teknolojilerin uygulama yazılımlarının niteliği ve açıklayıcı 
özelliklerinin iyileştirilmesi FeTeMM öğretim uygulamaları ile mobil teknolojilerin entegrasyonunu kolaylaştırabilir (Criollo-C, Guerrero-Arias, Jaramillo-Alcázar \& Luján-Mora, 2021). Mobil teknoloji araçlarında uygulama geliştiren programcılar özellikle sensör özelliklerin kullanıldığı uygulamalarda açıklayıcı ve örnek etkinlik sunumları eklerse bu entegrasyon sorunu aş1labilir.

Deney grubundaki öğretmen adayları FeTeMM öğretim modelinin tasarlama ve üretme aşamasında mobil teknolojiyi ölçme aracı olarak entegrasyonunda zorlanmışlardır. Öğretmen adaylarına FeTeMM uygulamalarından önce akıllı telefonlardaki sensör özelliklerini tanımaları için basit fen deneyleri yaptırılmıştır. Örneğin bir FeTeMM etkinliği olarak rüzgar türbini tasarımından önce öğretmen adaylarına telefonlarla farklı parlaklıktaki lambaların 1şık şiddetleri ölçtürülmüştür. Daha sonra öğretmen adaylarından bir rüzgar türbini tasarlamaları ve türbinin dönüş hızını bulmaları istenmiştir. Ancak öğretmen adayları telefonun 1şık şiddetini ölçen sensör özelliğini türbinin dönüş hızını ölçmede eksik kalmışlardır. Çünkü öğretmen adayları FeTeMM tasarımından önce basit fen deneyinde ak1llı telefonun sensörüyle doğrudan ölçme yaparken FeTeMM tasarımında aynı sensörü dolaylı ölçüm aracı olarak kullanması gerekiyordu. Buradan akı1lı telefonların doğrudan ölçme ile dolaylı ölçmede nasıl kullanılması gerektiği konusunda bir eksiklik ortaya çıkmıştır. $\mathrm{Bu}$ kapsamda öğretmen adaylarına akıllı telefonların sensör özelliklerinin tanıtıldığı basit fen deneylerine ek olarak dolaylı ve doğrudan ölçme becerileri de kazandırılmalıdır. Mobil-FeTeMM öğretim modeli, kapsamlı ölçme becerileri kazanmış ögretmen adaylarıyla ancak bu durumda hayata geçirilebilir.

FeTeMM etkinliklerinde mobil teknolojiler öğrenciyi merkeze alan önemli araçlardır ve öğrenciye çoklu öğrenme modelleri sunar. Yenilikçi özelliğinden ve sürekli güncellenmesinden dolayı mobil teknolojiler doğasında sorunludur. Fakat doğal sorunlu yapısına rağmen kullanımı gün geçtikçe artmaktadır. Mobil teknolojiler gelecekte günlük yaşamda önemi daha da artacaktır (Criollo-C vd., 2021). Özellikle laboratuvarlarda, sinıflarda ve günlük hayatta önemli bir veri kaydedici ve ölçme cihazı olarak önemli olacağı tahmin edilmektedir. Bu çalışmada mobil teknolojinin FeTeMM etkinliklerinde kullanımına yönelik olumsuz sonuçla karşı karşıya kalınsa da ileriki çalışmalarda bu çalışmada ortaya konulan noktalarda iyileştirmeler yapılarak bir kazanç sağlanabilir. Öğretmenler ve öğretmen adayları yaratıcılıklarını kullanarak akıllı telefondaki sensörler ile fizik, biyoloji ve kimya alanındaki çeşitli konularda pratik çalışmalar yapabilirler (Chu, Ong, Ayop, Mohd Azmi, Shah Abdullah, Abd Karim \& Tho, 2021). Özellikle mobilFeTeMM tasarımlarının ilk aşamalarında öğretmen adayları sorun yaşadıkları için bu aşamalara yönelik bu teknolojilerin sensör özelliklerinin entegre edildiği eğitimleri alması önerilir. Bu kapsamda mobil teknolojilerin FeTeMM öğretim uygulamalarında öğretime uygun şekilde entegre edilmesi için ek çaba gösterilmelidir.

\section{Kaynaklar}

Ally, M. (2007). Guest editorial-mobile learning. The International Review of Research in Open and Distributed Learning, 8(2), 1-4. Doi: https://doi.org/10.19173/irrodl.v8i2.451.

Altan, E. B., Yamak, H., \& Kırıkkaya, E. B. (2016). FeTeMM eğitim yaklaşımının öğretmen eğitiminde uygulanmasına yönelik bir öneri: tasarım temelli fen eğitimi. Trakya Üniversitesi Ë̆itim Fakültesi Dergisi, 6(2), 212-232.

Ariffin, S. A., Sidek, S. F., \& Mutalib, M. F. H. (2018). A preliminary investigation of Malaysian student's daily use of mobile devices as potential tools for STEM in a local university context. International Journal of Interactive Mobile Technologies (IJIM), 12(2), 80-91. Doi: https://doi.org/10.3991/ijim.v12i2.8015. 
Asunda, P. A. (2012). Standards for technological literacy and STEM education delivery through career and technical education programs. Journal of Technology Education, 23(2), 44-60. Doi: https://doi.org/10.21061/jte.v23i2.a.3.

Atılgan, D. (2006). İletişim teknolojileri çağında değişen bilgi hizmetleri. 1. Uluslararası Bilgi Hizmetleri Sempozyumu, İstanbul.

Balay, R. (2004). Küreselleşme, bilgi toplumu ve eğitim. Ankara Üniversitesi Ĕgitim Bilimleri Fakültesi Dergisi, 37(2), 61-82. Doi: https://doi.org/10.1501/egifak_0000000097.

Balc1, A. (2009). Sosyal bilimlerde araştırma: yöntem, teknik ve ilkeler. Ankara: Pegem Akademi.

Baran, T., \& Kahraman, S. (2004). Mühendislik eğitiminde probleme dayalı öğrenme modelleri. I. Ulusal Mühendislik Kongresi, İzmir.

Briz-Ponce, L., Pereira, A., Carvalho, L., Juanes-Méndez, J. A., \& García-Peñalvo, F. J. (2017). Learning with mobile technologies-Students' behavior. Computers in Human Behavior, 72, 612-620. Doi: https://doi.org/10.1016/j.chb.2016.05.027.

Brunsell, E. (2012). Integrating engineering and science in your classroom. Arlington, VA: NSTA Press.

Bozkurt, A., \& Özyurt, M. (2019). Investigate the evaluations of prospective teacher on STEM education, based on their experiences with planning and implementing STEM activities. Malaysian Online Journal of Educational Technology, 7(4), 81-97. Doi: https://doi.org/10.17220/mojet.2019.04.006.

Burrus, S. C. (2009). "Connexions Project" adl projede "What is Enginnering?” başlığında sunulan rapordur.20.11.2021 tarihinde https://cnx.org/contents/JD0DSZ35@2/What-isEngineering adresinden erişildi.

Büyüköztürk, Ş., Çakmak, E. K., Akgün, Ö. E., Karadeniz, Ş., \& Demirel, F. (2014). Bilimsel araştırma yöntemleri (17. baskı). Ankara: Pegem Yayınları.

Bybee, R. W. (2011). Scientific and engineering practices in k-12 classrooms: Understanding "a framework for k-12 science education". Science and Children, 49(4), 10-16.

Bybee, R. W. (2010). What is STEM education. Science, 329, 996. Doi: https://doi.org/10.1126/science.1194998.

Bybee, R. W. (2013). The case for STEM education: Challenges and opportunities. Arlington, VA: NSTA Press.

Cohen, J. (1992). A power primer. Psychological Bulletin, 112(1), 155-159. Doi: https://doi.org/10.1037/0033-2909.112.1.155.

Chiong, C., \& Shuler, C. (2010). "The Joan Ganz Cooney Center at Sesame Workshop" adlı çalıştayda "Learning: Is there an app for that? Investigations of young children's usage and learning with mobile devices and apps" başlığında hazırlanan çalışmanın raporu. 20.11.2021 tarihinde http://www-tc.pbskids.org/read/files/cooney_learning_apps.pdf adresinden indirildi.

Chou, C. C., Block, L., \& Jesness, R. (2012). A case study of mobile learning pilot project in K12 schools. Journal of Educational Technology Development and Exchange (JETDE), 5(2), 3. Doi: https://doi.org/10.18785/jetde.0502.02.

Chu, W. W., Ong, E. T., Ayop, S. K., Mohd Azmi, M. S., Shah Abdullah, A., Abd Karim, N. S., $\&$ Tho, S. W. (2021). The innovative use of smartphone for sound STEM practical kit: a pilot implementation for secondary classroom. Research in Science \& Technological Education, 1-23. Doi: https://doi.org/10.1080/02635143.2021.1978963. 
Mobil-FeTeMM Öğretim Uygulamalarının Öğretmen Adaylarının Mühendislik Tasarım Süreç Becerilerine Etkisi

Criollo-C, S., Guerrero-Arias, A., Jaramillo-Alcázar, A., \& Luján-Mora, S. (2021). Mobile learning technologies for education: Benefits and pending issues. Appl. Sci., 11, 4111(117). Doi: https://doi.org/10.3390/app11094111.

Çark, Ö. (2020). Dijital dönüşümün işgücü ve meslekler üzerindeki etkileri. International Journal Entrepreneurship and Management Inquiries, 4(1), 19-34.

Çepni, S. (2007). Araştırma ve proje çalışmalarına giriş. Trabzon: Celepler Matbaacılık.

Çokluk, Ö., Şekercioğlu, G., \& Büyüköztürk, Ş. (2012). Sosyal bilimler için çok değişkenli istatistik SPSS ve LISREL uygulamaları (2. bask1). Ankara: Pegem.

Çorlu, M. S. (2014). FeTeMM eğitimi makale çağrı mektubu. Turkish Journal of Education, 3(1), 4-10. Doi: https://doi.org/10.19128/turje.181071.

Daugherty, J. (2012). "National Center for Engineering and Technology Education" adlı kurumun "Infusing engineering concepts: Teaching engineering design" başlığında yayımlanan raporu. 20.11.2021 tarihinde http://files.eric.ed.gov/fulltext/ED537384.pdf adresinden erişildi.

Delen, İ., \& Uzun, S. (2018). Matematik öğretmen adaylarının FeTeMM temelli tasarladıkları öğrenme ortamlarının değerlendirilmesi. Hacettepe Üniversitesi Ĕgitim Fakültesi Dergisi, 33(3), 617-630. Doi: https://doi.org/10.16986/HUJE.2018037019.

Dugger, W. E. (2010). Evolution of STEM in the United States. 6th Biennial International Conference on Technology Education Research, Queensland, Australia.

English, L. D., King, D., \& Smeed, J. (2017). Advancing integrated STEM learning through engineering design: Sixth-grade students' design and construction of earthquake resistant buildings. Journal of Educational Research, 110(3), 255-271. Doi: https://doi.org/10.1080/00220671.2016.1264053.

Erkorkmaz, Ü., Etikan, İ., Demir, O., Özdamar, K., \& Sanisoğlu, S. Y. (2013). Doğrulayıcı faktör analizi ve uyum indeksleri. Türkiye Klinikleri Tip Bilim Dergisi, 33(1), 210-223. Doi: https://doi.org/10.5336/medsci.2011-26747.

Gonzalez, H. B., \& Kuenzi, J. J. (2012). "Congressional Research Service” adlı kurumun "Science, technology, engineering, and mathematics (STEM) education: A primer" başlıklı kongrre raporu. 20.11.2021 tarihinde http://steamwise.io/docs/congressionalresearch-service-R42642.pdf adresinden erişildi.

Gündüz, Ş., \& Odabaşı, Ş. (2004). Bilgi çağında öğretmen adaylarının eğitiminde öğretim teknolojileri ve materyal geliştirme dersinin önemi. The Turkish Online Journal of Educational Technology, 3(1), 43-48.

Haik, Y., \& Shahin, T. (2010). Engineering design process ( $3^{\text {rd }}$ ed.). USA: Cengage Learning.

Hamida, S. T. B., Hamida, E. B., \& Ahmed, B. (2015). A new mHealth communication framework for use in wearable WBANs and mobile technologies. Sensors, 15(2), 33793408. Doi: https://doi.org/10.3390/s150203379.

Hiğde, E., Keleş, F., \& Aktamış, H. (2020). STEM alanlarına ve öğretimine yönelik tutumları inceleyen model çalışması. Bolu Abant İzzet Baysal Üniversitesi Eğitim Fakültesi Dergisi, 20(2), 1145-1160. Doi: https://doi.org/10.17240/aibuefd.2020-648229.

Karasar, N. (1988). Bilimsel araştırma yöntemi. Ankara: Nobel Yayın Dağıtım. 
Kearney, M., \& Maher, D. (2013). Mobile learning in math teacher education: using ipads to support pre-service teachers' professional development. Australian Educational Computing, 27(3), 76-84.

Kennedy, T. J., \& Odell, M. R. L. (2014). Engaging students in STEM education. Science Education International, 25(3), 246-258.

Kirschner, P., \& Selinger, M. (2003). The state of affairs of teacher education with respect to information and communications technology. Technology, Pedagogy and Education, 12(1), 5-17. Doi: https://doi.org/10.1080/14759390300200143.

Kline, R. B. (2011). Principles and practice of structural equation modeling (3rd. ed.). New York, NY: Guilford.

Kolodner, J. L. (2002). Facilitating the learning of design practices: Lessons learned from an inquiry into science education. Journal of Industrial Teacher Education, 39(3), 9-40.

Kukulska-Hulme, A. (2009). Conclusions: future directions in researching mobile learning. V. Giasemi; P. Norbert \& K. Agnes (eds.). Researching mobile learning: frameworks, tools and research designs. Oxford, UK: Peter Lang Verlag.

Lehner, F., \& Nosekabel, H. (2002). The Role of mobile devices in e-learning first experiences with a wireless e-learning environment. IEEE International Workshop on Wireless and Mobile Technologies in Education, Tokushima, Japan.

Liu, T. C., Peng, H., Wu, W. H., \& Lin, M. S. (2009). The effects of mobile natural-science learning based on the 5E learning cycle: A case study. Journal of Educational Technology \& Society, 12(4), 344-358.

Lou, S. J., Shih, R. C., Diez, C. R., \& Tseng, K. H. (2011). The impact of problem-based learning strategies on STEM knowledge integration and attitudes: an exploratory study among female Taiwanese senior high school students. International Journal of Technology and Design Education, 21(2), 195-215. Doi: https://doi.org/10.1007/s10798-010-9114-8.

Marulcu, İ. (2010). Investigating the impact of a LEGO ${ }^{\mathrm{TM}}-$ based, engineering-oriented curriculum compared to an inquiry-based curriculum on fifth graders' content learning of simple machines (Yayımlanmamıs doktora tezi). Lynch School of Education, Boston College, USA.

Mentzer, N., Becker, K., \& Sutton, M. (2015). Engineering design thinking: high school students' performance and knowledge. Journal of Technology Education, 104, 417-432. Doi: https://doi.org/10.1109/ICL.2015.7318218.

Miaoulis, I. N. (2009). Engineering the K-12 curriculum for technological innovation. IEEEUSA Today's Engineer Online. 3 May1s 2013 tarihinde http://www.todaysengineer.org/2009/Jun/K-12-curriculum.asp sayfasından erişildi.

Milli Eğitim Bakanlığ 1 (MEB, 2018). Fen bilimleri dersi öğretim programı (ilkokul ve ortaokul 3, 4, 5, 6, 7 ve 8. siniflar). Ankara: Talim ve Terbiye Kurulu Başkanlığı.

Moazzen, I., Miller, M., Wild, P., Jackson, L., \& Hadwin, A. F. (2014). Engineering design survey. Canadian Engineering Education Association (CEEA14) Conference, Canmore. Doi: https://doi.org/10.24908/pceea.v0i0.5892.

National Research Council (NRC, 2012). A Framework for $k$-12 science education: practices, crosscutting concepts, and core ideas. Washington DC: The National Academic Press.

Nithia, K., Yusop, F. D., \& Razak, R. A. (2015). Mobile learning for teaching and learning Science, Technology, Engineering and Mathematics (STEM): A review of literature. 
Economics, Social Sciences and Information Management (November), 173-176. Doi: https://doi.org/10.1201/b19921-29.

Nunn, J. (2016). Having fun with a cordless mouse. Physics Education, 51(4). Doi: https://doi.org/10.1088/0031-9120/51/4/045011.

Ryan, M., Camp, P., \& Crismond, D. (2001). Design rules of thumb-connecting science and design. Meetings of the American Educational Research Association, Seattle, WA.

Sanders, M. (2009). STEM, STEM education, STEMmania. The Technology Teacher, 20-26.

Okur, M. (2021). Fen bilgisi öğretmen adaylarının mobil teknolojilerin laboratuvar ortamında kullanılmasına yönelik görüşlerinin değerlendirilmesi. YYÜ Eğitim Fakültesi Dergisi, 18(1), 982-1008. Doi: https://doi.org/10.33711/yyuefd.957382.

Özdamar, K. (2002). Paket programlartyla istatistiksel veri analizi. Eskişehir: Kaan Kitabevi.

Tabachnick, B. G., \& Fidell, L. S. (2001). Using multivariate statistics. Boston: Allyn and Bacon.

Tantu, Ö. (2017). Evaluating mobile apps for STEM education with in-service teachers (Yayımlanmamış doktora tezi), Orta Doğu Teknik Üniversitesi, Ankara.

Taşdemir, C., \& Kaya, N. (2009). Mühendislik eğitimi. 1. İnşaat Mühendisliği Eğitimi Seтроzуити, Antalya.

Tayal, S. P. (2013). Engineering design process. International Journal of Computer Science and Communication Engineering, 1-5.

Tomczak, M., \& Tomczak, E. (2014). The need to report effect size estimates revisited. An overview of some recommended measures of effect size. Trends in Sport Sciences, 1(21), 19-25.

Topalsan, A. K. (2018). Sınıf öğretmenliği öğretmen adaylarının geliştirdikleri mühendislik tasarım temelli fen öğretim etkinliklerinin değerlendirilmesi. Yüzüncü Yll Üniversitesi Eğitim Fakültesi Dergisi, 15(1), 186-219. Doi: https://doi.org/10.23891/efdyyu.2018.66.

Toulmin, C., \& Groome, M. (2007). "National Governor's Association” adl kurumun "Building a science, technology, engineering, and math agenda" başlığında yayımlanan raporu. 20.11.2021 tatrihinde https://files.eric.ed.gov/fulltext/ED496324.pdf adresinden erişildi.

Traxler, J. (2007). Defining, discussing, and evaluating mobile learning: the moving finger writes and having writ... . The International Review of Research in Open and Distributed Learning, 8(2), 1-8. Doi: https://doi.org/10.19173/irrodl.v8i2.346.

Yamak, H., Bulut, N., \& Dündar, S. (2014). 5. sınıf öğrencilerinin bilimsel süreç becerileri ile fene karşı tutumlarına FeTeMM etkinliklerinin etkisi. GEFAD / GUJGEF, 34(2), 249265. Doi: https://doi.org/10.17152/gefd.15192.

Yenilmez, K., \& Balbağ, Z. (2016). Fen bilgisi ve ilköğretim matematik öğretmeni adaylarının STEM'E yönelik tutumları. Ë̆itim ve Öğretim Araştırmaları Dergisi, 5(4), 301-307.

\section{EXTENDED ABSTRACT}

\section{Introduction}

Today, the rapid increase in technological and scientific developments has revealed the need for individuals who research, produce, question, think creatively and analytically in societies that want to keep up with the innovations required by the age. In parallel with the development of 
technology, most societies are turning to innovative approaches supported by technology in their educational programs. To use technology effectively in STEM teaching practices, qualified and equipped teachers with pedagogical and content knowledge as well as engineering design skills should be trained. The use of technologies such as TV and computer as presentation material is more intense than mobile technologies. In this sense, the use of mobile technologies including smartphones in schools can be considered relatively new. Mobile technologies have started to be a part of life since the 2000s and have recently taken the place of computers actively, affecting daily life. Today, most children are faced with computers and mobile technologies at an early age and become familiar with mobile technologies from a very young age. In this sense, mobile technologies are a fact of daily life, an indispensable part of daily life for both students and parents. Access to information has become so easy today; however, it has become more difficult to access the right needed information. At this point, mobile technologies can be helpful in accessing information under teacher control. The easy use and sharing of communication and media environments in mobile technologies have been a major factor in the spread and development of technology. The rapid development of mobile technologies has revealed the need to improve the information, communication and technology competencies of teachers and students in education. The unique opportunities of mobile learning for better education can be listed as follows: - It provides learning regardless of time and place, - It provides access to lowincome students, -improves 21 st-century communication skills, -facilitates learning in different learning environments and -can be adapted to each student in a way that eliminates individual differences.

To be open to innovation, countries have made a reform movement in the field of education with the STEM teaching approach in order to better train future engineers, scientists and mathematicians. STEM can be defined as a process in which science, technology, engineering and mathematics disciplines are taught in an integrated way when produced multiple solutions are produced for problems related to daily life. Simultaneously, the STEM can also be defined as a process that includes technology-based engineering design, inquiry, problem-based learning and project-based learning approaches. Conducting science courses within the framework of daily life problems according to the engineering design process not only allows students to learn the targeted science concepts and achievements meaningfully, but also improves students' conceptual understanding of the engineering discipline and engineering design process skills.

Engineers refer to the engineering design process to effectively solve the problems faced by society. The engineering design process is a series of steps that an engineer uses during the design development phase to solve a problem. The developed design is constantly reviewed and revised considering new information learned throughout the process. The main purpose in the engineering design process is to evaluate possible designs and choose the most effective one among the alternative designs developed. Engineering design in science education is a process where students develop more than one alternative design for a determined problem, use their high-level thinking skills, produce solutions to daily life problems, and work collaboratively.

Engineering design processes are important in STEM teaching in terms of the permanence of the learned knowledge and the application field of the knowledge. When students have an education process towards engineering design processes in STEM teaching, they can gain the ability to question systematically and produce multiple solutions to the problems encountered in daily life. However, some studies on STEM teaching practices showed that students have difficulties in "definition of the problem", "development the new design", "development of the alternative design", "evaluation of design" and "revision processes of the design". In such a case, the advantageous aspects of mobile technologies can help students in their engineering design processes. However, the disadvantages of mobile technologies can also negatively affect engineering design processes. In line with this dilemma, the study aimed at examining the effects 
Mobil-FeTeMM Öğretim Uygulamalarının Öğretmen Adaylarının Mühendislik Tasarım Süreç Becerilerine Etkisi

of mobile technology-based STEM (mobile-STEM) teaching practices on pre-service teachers' engineering design process skills.

\section{Purpose}

In studies on STEM teaching, the difficulties experienced by students in the design process were mentioned, but experimental studies examining the effects of STEM teaching implementations on engineering design processes were limited. In this context, to contribute to this deficiency in the literature, this study examined the effects of mobile technology-based STEM (mobile-STEM) implementations on the engineering design process skills of pre-service teachers. Therefore, the problem sentence of the study was defined as follows: "Does mobile-STEM teaching implementations affect the engineering design process skills of pre-service teachers?"

\section{Method}

The study was designed by pre-test-post-test nonequivalent control group quasi-experimental research model from experimental research models. The participants were pre-service teachers in two different classes formed formally Dokuz Eylül University Buca Eğitim Fakültesi Science Teacher Education Department. At the beginning of the academic semester, a class was assigned randomly as the experimental group (n: 45) and the other class as the control group (n:25). While the mobile-STEM teaching implementations were applied in the experimental group, only STEM teaching implementations were realized in the control group. In this study, the adapted Turkish form of the "Engineering Design Process Skills Scale (EDPSS)" was used. This scale is the first part of the two-part "Engineering Design Survey" developed by Moazzen, Miller, Wild, Jackson, Hadwin (2014). The normal distribution of the EDPSS, which consists of 61 items, was calculated using the Kolmogorov-Smirnov and Shapiro-Wilk tests. Since the scores calculated in the total and sub-dimensions of this did not provide the normality distribution and the number of participants in the control group was less than 30 people, the data were analyzed with the MannWhitney U (MWU) test. For this purpose, the total posttest and pretest difference scores of the EDPSS were used in the MWU analysis.

\section{Findings}

The study results showed that total post-test and pre-test difference scores of EDPSS between the experimental and control groups were significant in favor of the control group (U=392.0, $\mathrm{p}=0.037$ ). According to this result, the engineering design process skills of the pre-service teachers who designed activities with mobile-STEM teaching implementations in the experimental group were less than the development of the control group. In the study, the scores of sub-dimensions such as "Setting targets $(\mathrm{U}=360.5, \mathrm{p}=0.013)$ ", "Making a plan $(\mathrm{U}=265.0$; $\mathrm{p}=0.000)$ ", "Collecting knowledge" ( $\mathrm{U}=252.5,0.000)$ " and "Alternative design production $(\mathrm{U}=385.0, \mathrm{p}=0.029)$ " in the EDPSS showed that there was a statistically significant difference in favor of the control group. Additionally, the change in the attitudes of the engineering design process skills toward the dimensions of choosing alternative designs, creating a model, revising the design, reporting and presentation processes was similar in both groups and there was no significant difference between the groups. Thus, the experimental group exhibited the same skills as the control group in the dimensions of alternative design selection, modeling, design revision, reporting and presentation. 


\section{Discussion and Conclusion}

In this study, the effect of mobile-STEM teaching implementations on the engineering design process skills of teacher candidates was examined. For this purpose, the engineering design process skills of the pre-service teachers were measured using 61-item EDPSS. The Mann Whitney $\mathrm{U}$ analysis was performed according to the posttest and pretest difference scores of the total and sub-dimensions of MSDS between the experimental and control groups, and some results were obtained in favor of the control group. Overall a result that was out of the expected estimations were encountered, and consequently, the study showed that integrating mobile technology into STEM teaching implementations in the experimental group did not improve engineering design process skills positively. The technology dimension, a component of STEM teaching model, seems to be a problematic dimension in practices and designs. STEM researchers and teachers using the STEM teaching model should focus on the technology dimension and produce their solutions at this point. Pre-service teachers who want to reach their educational purposes with STEM teaching implementations should use the sensor features of mobile technologies effectively and develop their design skills. Other sides, the pre-service teachers in both the experimental and control groups had difficulties in modelling STEM projects and could not perform adequately in revising their design models.

\section{Ethics Committee Permission}

This study was conducted by the "Higher Education Institutions Scientific Research and Publication Ethics Rules." Ethics committee permission for this study was obtained with the decision number 12 of the Ethics Committee Commission of Dokuz Eylul University Institute of Educational Sciences on 23.11.2017. 